\title{
Causes of blindness and visual handicap in the Central African Republic
}

\author{
Andrew R Potter
}

\begin{abstract}
The causes of bilateral blindness (best visual acuity less than $3 / 60$ ) in 1371 people in the Central African Republic seen between 1985 and 1989 who attended eye clinics in 10 out of the 16 prefectures across the country are given. The main causes of bilateral blindness were cataract $(51 \%)$, glaucoma $(12.7 \%)$, and onchocerciasis $(8 \cdot 1 \%)$. In 710 patients with unilateral blindness the main causes were cataract $(38 \%)$, glaucoma $(10 \%)$, iritis $(7 \cdot 5 \%)$, and trauma $(6 \cdot 3 \%)$. Bilateral blindness in children was rarely seen. The causes of visual impairment (vision between $6 / 18$ and $3 / 60$ ) in 424 patients were cataract, including aphakia (38\%), maculopathy (14\%), and onchocerciasis (7\%).
\end{abstract}

The Central African Republic is considered one of the poorest 20 countries in the world with a gross national product of 290 US\$ per head in 1986. It is a large landlocked country 622436 $\mathrm{km}^{2}$, two and a half times the size of the United Kingdom but with a population of less than 3 million in 1988. Life expectancy is estimated at 44 years, with a child mortality rate of 232 . Health care is provided by the government medical service through hospitals in the larger towns and by an extensive network of voluntary church based hospitals and dispensaries.

The majority of people live by subsistence farming. The main crops are cassava, peanuts, bananas, plantains, maize, and rice. In certain areas cotton, coffee, and tobacco are produced as cash crops. In addition timber and diamonds are also exported.

The climate is tropical with little variation. Rains except in the far north of the country, are adequate, with an average of 60 inches (1500 $\mathrm{mm}$ ) per year. The rainy season is from March until October.

Table 1 Causes of blindness in all age groups

\begin{tabular}{lrrrr}
\hline & & & \multicolumn{2}{l}{ Total } \\
\cline { 5 - 5 } Causes of blindness & $\begin{array}{l}\text { Male } \\
n=887\end{array}$ & $\begin{array}{c}\text { Female } \\
n=484\end{array}$ & $n=1371$ & $\%$ \\
\hline Cataract, including & & & & \\
uncorrected aphakia & 430 & 267 & 697 & $50 \cdot 8$ \\
Glaucoma & 125 & 49 & 174 & $12 \cdot 7$ \\
Onchocerciasis & 90 & 21 & 111 & $8 \cdot 1$ \\
Optic atrophy & 44 & 29 & 73 & $5 \cdot 3$ \\
Iritis & 39 & 24 & 63 & $4 \cdot 6$ \\
Corneal scar & 34 & 21 & 55 & $4 \cdot 0$ \\
Phthisis bulbi & 20 & 20 & 40 & $2 \cdot 9$ \\
Trichiasis & 7 & 16 & 23 & $1 \cdot 7$ \\
Maculopathy & 16 & 4 & 20 & $1 \cdot 46$ \\
Retinopathy & 12 & 2 & 14 & $1 \cdot 0$ \\
Band keratopathy & 6 & 2 & 8 & $0 \cdot 55$ \\
Retinitis pigmentosa & 2 & 5 & 7 & $0 \cdot 51$ \\
Traditional medicines & 2 & 5 & 7 & $0 \cdot 51$ \\
Retinal detachment & 5 & 1 & 6 & $0 \cdot 44$ \\
Leprosy & 4 & 1 & 5 & $0 \cdot 36$ \\
Undiagnosed & 15 & 2 & 17 & $1 \cdot 24$ \\
All other causes & 36 & 15 & 51 & $3 \cdot 83$ \\
\hline
\end{tabular}

Most of the population is well nourished, and child malnutrition is uncommon. The local diet is rich in palm oil, fresh fruits, and green leafy vegetables, so that vitamin A deficiency is rarely seen.

Ophthalmic services are poorly developed. There is a department of ophthalmology at the university hospital in the capital Bangui, with one full-time expatriate ophthalmologist. In the extreme north-west of CAR, near the border with Cameroon and Chad, there is a general physician who also performs eye surgery. Once a year a surgical team from West Germany spends one month visiting three or four provincial towns holding eye clinics and performing eye surgery.

\section{Patients and methods}

Between 1985 and 1989 the author visited 19 provincial hospital dispensaries and centres in 10 of the 16 prefectures, covering all regions except the sparsely populated north of CAR. A total of 7479 ophthalmic consultations were recorded. Visual acuity was recorded on both eyes of all patients. Causes of bilateral and unilateral blindness (visual acuity less than $3 / 60$ ) and of visual impairment (visual acuity between $6 / 18$ and $3 /$ 60) were recorded.

\section{Results}

Table 1 lists the major causes of blindness in 1371 blind patients attending eye clinics across CAR between 1985 and 1989. Cataract and uncorrected aphakia accounted for half the blindness. The ratio of blind men to women was 2:1. Onchocerciasis was four times more common in men than women. Trichiasis was twice as common in women as men. Glaucoma was twice as common in men.

Table 2 lists the causes of bilateral blindness in 30 blind children seen at the clinics. Corneal scar or phthisis bulbi accounted for $20 \%$ and congenital cataract for $13 \cdot 5 \%$.

The causes of unilateral blindness are given in Table 3. Cataract $(38 \%)$ and glaucoma $(10 \%)$ were the major causes. Trauma, onchocerciasis, and optic atrophy were seen more frequently in

Table 2 Causes of bilateral blindness in children (0-15 yr)

\begin{tabular}{lcc}
\hline Causes of blindness & Number & $\%$ \\
\hline Corneal scar & 5 & 17 \\
Cataract & 4 & $13 \cdot 5$ \\
Optic atrophy & 4 & $13 \cdot 5$ \\
Iritis & 3 & 10 \\
Microphthalmia & 3 & 10 \\
Glaucoma & 2 & 7 \\
Trachoma & 1 & $3 \cdot 5$ \\
Phthisis bulbi & 1 & $3 \cdot 5$ \\
Other single causes & 7 & 22 \\
Total & 30 & 100 \\
\hline
\end{tabular}


Table 3 Causes of unilateral blindness in all age groups

\begin{tabular}{lcccc}
\hline & & & \multicolumn{2}{c}{ Total } \\
\cline { 4 - 5 } Causes of blindness & $\begin{array}{c}\text { Male } \\
n=499\end{array}$ & $\begin{array}{c}\text { Female } \\
n=211\end{array}$ & $n=710$ & $\%$ \\
\hline Cataract & 194 & 77 & 271 & 38 \\
Glaucoma & 50 & 21 & 71 & 10 \\
Corneal scar & 49 & 17 & 66 & $9 \cdot 3$ \\
Iritis & 30 & 23 & 53 & $7 \cdot 5$ \\
Trauma & 35 & 10 & 45 & $6 \cdot 3$ \\
Onchocerciasis & 33 & 8 & 41 & $5 \cdot 8$ \\
Phthisis bulbi & 14 & 13 & 27 & $3 \cdot 8$ \\
Optic atrophy & 24 & 2 & 26 & $3 \cdot 6$ \\
Maculopathy & 11 & 8 & 19 & $2 \cdot 7$ \\
Trichiasis & 7 & 8 & 15 & $2 \cdot 0$ \\
Other causes & 52 & 24 & 76 & $11 \cdot 0$ \\
Total & 499 & 211 & 710 & 100 \\
\hline
\end{tabular}

Table 4 Causes of unilateral blindness in children (0-15 yr)

\begin{tabular}{lcc}
\hline Causes of blindness & Number & $\%$ \\
\hline Trauma & 8 & 27 \\
Corneal scar & 5 & 17 \\
Cataract & 5 & 17 \\
Phthisis bulbi & 4 & 13 \\
Other & 8 & 26 \\
Total & 30 & 100 \\
\hline
\end{tabular}

Table 5 Causes of visual handicap in all age groups

\begin{tabular}{lcccc}
\hline & & & \multicolumn{2}{c}{ Total } \\
\cline { 4 - 5 } Causes of blindness & $\begin{array}{c}\text { Male } \\
n=272\end{array}$ & $\begin{array}{c}\text { Female } \\
n=152\end{array}$ & $n=424$ & $\%$ \\
\hline Cataract, including & & & & \\
aphakia & 95 & 66 & 161 & 38 \\
Maculopathy & 41 & 19 & 60 & $14 \cdot 1$ \\
Onchocerciasis & 23 & 8 & 31 & $7 \cdot 3$ \\
Undiagnosed & 9 & 14 & 23 & $5 \cdot 4$ \\
Corneal scar & 13 & 4 & 17 & $4 \cdot 0$ \\
Iritis & 10 & 5 & 15 & $3 \cdot 5$ \\
Glaucoma & 14 & 1 & 15 & $3 \cdot 5$ \\
Refractive errors & 11 & 4 & 15 & $3 \cdot 5$ \\
Retinopathy & 9 & 4 & 13 & $3 \cdot 01$ \\
Entropion & 4 & 8 & 12 & $2 \cdot 8$ \\
Optic atrophy & 7 & 3 & 10 & $2 \cdot 35$ \\
Pterygium & 5 & 1 & 6 & $1 \cdot 4$ \\
Band keratopathy & 3 & 2 & 5 & $1 \cdot 1$ \\
All others & 28 & 13 & 41 & $10 \cdot 04$ \\
Total & 272 & 152 & 424 & 100 \\
\hline
\end{tabular}

men, whereas iritis, phthisis bulbi, maculopathy, and trichiasis were more common in women. Thirty children with unilateral blindness were seen. Corneal scar/phthisis bulbi (30\%), trauma $(27 \%)$, and cataract $(17 \%)$ were the major causes (Table 4).

In all prefectures visited, except Ouham in the north-west of CAR, cataract was the commonest cause of bilateral blindness. In Ouham the commonest cause was onchocerciasis. Cataract was also the commonest cause of visual handicap (vision between $6 / 18$ and $3 / 60$ ) which, together with aphakia, contributed $38 \%$ of poor sight (Table 5).

\section{Discussion}

This survey is based on patients presenting to hospitals and clinics over a wide area of the Central African Republic between 1985 and 1989. There is therefore a bias to treatable conditions. For example, many have sought medical advice before and been told that there was no treatment possible. However, in several places visited no previous eye clinics have ever been held, and the incurably blind often retain the hope that a new doctor will, after all, be able to help them.

Not every prefecture in CAR was visited and these results cannot represent fully the spectrum of blindness and visual handicap in the country. No study of the prevalence of blindness in CAR has yet been published.

Surveys from The Gambia, Tanzania, Chad, Ethiopia, Nigeria, Ghana, Kenya, and Malawi ${ }^{1-7}$ all confirm cataract as the major cause of blindness in adults. However, variations in the major causes of blindness do occur owing to geographical and climatic differences. In dry areas trachoma is important, causing blindness from trichiasis and corneal scarring. In areas with fast flowing rivers onchocerciasis may occur. In countries with low rainfall, poor nutrition, and low measles immunisation coverage xerophthalmia may be frequently seen in children.

Cataract is the single most important cause of blindness in CAR and it accounts for half of the blind patients in this survey. If we assume a prevalence of blindness of $1 \%$ (similar to studies in other African countries - for example, The Gambia $0.7 \%$, Kenya $0.9 \%$, Chad $2 \cdot 31 \%$, Malawi 1.3\%) then there are an estimated 28600 blind people in CAR, half of whom are blind from cataract (approximately 14000). Most of these people could have their sight restored through cataract surgery with aphakic spectacle correction. During the period 1985-9 there were three resident surgeons performing cataract surgery in CAR, and it is estimated that fewer than 500 patients were benefiting from sight restoring surgery per year. There is at present no optical workshop in CAR and all aphakic spectacles have to be imported (there are plans to start a workshop in Bangui).

It is unlikely that in the foreseeable future sufficient ophthalmologists will be available in CAR to deal with the cataract problem. Many of the blind live in rural communities and cannot travel to the capital city. One possible solution is to develop mobile teams of eye workers who will visit provincial hospitals to consult and provide surgery for the curably blind. General physicians and surgical nurses may be trained to perform intracapsular cataract extractions under local anaesthetic. Inexpensive aphakic spectacles (standard +10.00 or +11.00 ) will need to be made available to patients after cataract surgery.

Glaucoma accounts for $13 \%$ of blindness. Prevention of blindness from glaucoma poses a real problem in the developing world. Diagnosis depends on measuring intraocular pressure, examining the optic discs, and detecting visual field defects. Foster et al have shown that it is possible to train nurses to use the ophthalmoscope and examine the optic discs for pathological cupping. ${ }^{8}$ Surgical management by trabeculectomy appears the most practical therapy for rural patients in Africa, where supplies of pressure lowering drugs are erratic and expensive and where patient compliance is low.

Most interestingly, although onchocerciasis is the third cause of bilateral blindness, it is the predominant cause in the prefecture of Ouham, north-west CAR. It was only in this area that microfilariae were seen in the aqueous humour of patients. Further studies in this region should be undertaken with a view. to mapping out the endemic focus, so that long term distribution of ivermectin can be undertaken. It is hard to know how much of the optic atrophy found in CAR is 
related to onchocerciasis (and attempts to treat it with diethyl carbamazine). It would be interesting to see if with the introduction of ivermectin the number of new cases of optic nerve atrophy falls.

Few patients were seen with leprosy in CAR (six out of 3786 consultations in 1985-7). Blindness from leprosy is therefore rare, but it is often preventable if patients present in the early stages of the disease. Blindness from the topical application of traditional medication was also rarely seen, but with widespread education it could be abolished.

As few children with bilateral blindness were seen in the clinics it is hard to make much comment. Interestingly, however, blinding xerophthalmia was seen in only one patient during the first two years of the study (in a patient who had travelled from Zaire). This may be explained by the diet rich in vitamin $A$ that is eaten in the rural areas. However, no visits were made to the two northernmost prefectures, where the climate is much drier and the diet may be less rich in palm oil and green leafy vegetables.

Patients who present with old corneal scars often give unhelpful histories that make it hard to determine the cause of their blindness. Many are reluctant to admit using traditional medicines for fear of an unsympathetic hearing. ${ }^{9-12}$ Cataract and aphakia account for $38 \%$ of visual handicap, indicating again the pre-eminent position of cataract as a cause of visual impairment in Africa.

\section{CONCLUSIONS}

More than 14000 people are blind from treatable cataract in the Central African Republic. The lack of trained personnel to deal with this problem is a major obstacle to eye care. Doctors, nurses, and other medical workers need training in eye care, and selected interested medical personnel could be taught cataract surgery. The possibility of setting up mobile surgical teams should be considered. Ivermectin distribution programmes need to be urgently employed across CAR and especially in the north-west, to prevent further blindness in young and middle age adults from onchocerciasis. Health education, with reference to the treatability of cataract, the dangers of neglecting gradual loss of vision, and the dangers of applying traditional medicines to the eyes need to be implemented. Broadcasting information on national radio may be one way of achieving this.

I am grateful to $\mathrm{Mr}$ Allen Foster for reviewing the manuscript and I am grateful to Mr Allen Foster for reviewing the manuscript and assistance.

The work was funded by Christoffel-Blindenmission, West Germany.

1 Faal H, Minassian D, Sowa S, Foster A. National survey of blindness and low vision in The Gambia. Br 7 Ophthalmol 1989; 73: 82-7.

2 Foster A, Taylor J. Causes of blindness in rural Tanzania. East Afr $\mathcal{f}$ Ophthalmol 1986; 7: 3-9.

3 Blindness in Chad. WHO Weekly Epidemiological Record 1987; 62: 322-3.

4 Quana'a P, Alemu B, Alemayebu W. Causes of blindness in the eye department of an Addis Ababa Hospital. Ethiop Med $\mathcal{F}$ 1986; 24: 19-23.

5 Ayanru JO. Blindness in the Mid Western State of Nigeria. Trop Geogr Med 1974; 26: 325-32.

6 Chatterjee S. Blindness in Ghana. Ghana Med $\mathcal{F}$ 1970; 9: $314-5$.

7 Whitfield R, Schwab L, Ross-Degran D, Steinkuller P, Swartwood J. Blindness and eye disease in Kenya: ocular status survey results from the Kenya Rural Blindness status survey results from the Kenya Rural Blind

8 Foster A, Wormald R, van der Heide A, Templeton $K$. Evaluation of ophthalmoscopy by non-ophthalmologists in diagnosing chronic glaucoma in West Africa. Eye 1989; 3: $647-50$.

9 Chirambo MC, Tielsch JM, West KP, et al. Blindness and visual impairment in southern Malawi. Bull WHO 1986; 64 567-72.

10 Sauter JJM. Xerophthalmic and measles in Kenya. Thesis. 1976. Klinick voor Oogheelkunde, Riiks Universiteit Groningen, Netherlands.

11 McGlashan ND. Measles, malnutrition and blindness in Luapula province, Zambia. Trop Geogr Med 1969; 21 : 157-62.

12 Foster A, Sommer A. Childhood blindness from corneal ulceration in Africa: causes, prevention and treatment. Bull WHO 1986; 65: 619-23. 